\title{
Variation of $\mathrm{BMI}$ and anthropometric indicators of abdominal obesity in Brazilian adolescents from public schools, 2003-2008
}

\author{
Erica G Barros ${ }^{1}$, Rosangela A Pereira ${ }^{1}$, Rosely Sichieri ${ }^{2}$ and Gloria V da Veiga ${ }^{1, *}$ \\ 'Department of Nutrition, Federal University of Rio de Janeiro, Av. Carlos Chagas Filho 373, Centro de \\ Ciências da Saúde, bloco J/2 andar, Ilha do Fundão, Rio de Janeiro, RJ, Brazil, CEP 21941-590: \\ ${ }^{2}$ Department of Social Medicine, Rio de Janeiro State University, Rio de Janeiro, RJ, Brazil
}

Submitted 24 March 2012: Final revision received 24 October 2012: Accepted 1 November 2012: First published online 3 December 2012

\begin{abstract}
Objective: The aim of the present study was to compare BMI and anthropometric indicators of abdominal obesity in Brazilian adolescents from public schools between 2003 and 2008.

Design: A comparison of anthropometric indicators in adolescents was done based on two cross-sectional surveys conducted in 2003 ( $n$ 530) and in 2008 ( $n$ 498). BMI (= weight/height ${ }^{2}$ ), waist circumference (WC), hip circumference (HC), waist-to-hip ratio (WHR) and waist-to-height ratio (WHtR) were evaluated. The age-adjusted means were compared between the two studies by linear regression and the percentile values were compared by quantile regression. A $P$ value $<0.05$ was adopted for statistical significance.

Setting: Metropolitan area of Rio de Janeiro, Brazil.

Subjects: Two probabilistic samples of students aged 15-19 years old, from public schools.

Results: There was a decrease in boys' mean WC $(72.9 \mathrm{~cm} v .70 \cdot 9 \mathrm{~cm}, P=0.01)$ and an increase in girls' mean BMI $\left(21 \cdot 1 \mathrm{~kg} / \mathrm{m}^{2} v .22 \cdot 0 \mathrm{~kg} / \mathrm{m}^{2}, P=0 \cdot 03\right)$. Among boys, the WC, HC and WHtR percentiles were lower whereas the WHR percentiles were higher in 2008 than in 2003. Among girls, the percentiles of all measures were higher in 2008, except for WHR.

Conclusions: Anthropometric measures among boys tended to decrease, while among girls there was a tendency to increase from 2003 to 2008, indicating an important gender effect and a higher morbidity risk associated with excess body fat in girls. The school setting offers opportunities for interventions to address this situation.
\end{abstract}

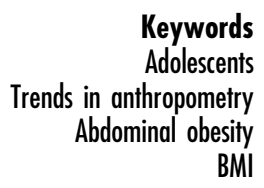

The prevalence of overweight and obesity in adolescents has been increasing over past years in many countries ${ }^{(1)}$, including Brazil, where in a period of 35 years (1974-1975 to 2008-2009) overweight in adolescents increased from $3 \cdot 7 \%$ to $21 \cdot 7 \%$ in boys and from $7 \cdot 6 \%$ to $19 \cdot 4 \%$ in girls ${ }^{(2)}$. This trend in overweight and obesity increase was also observed in 9-12-year-old public schools students investigated in a randomized clinical trial for prevention of obesity in the city of Niterói, Rio de Janeiro, comparing baseline and final data collected after one school year ${ }^{(3)}$. On the other hand, the prevalence of underweight decreased among Brazilian adolescents reaching about $3 \%$ among boys and girls in 2008-2009 ${ }^{(2)}$.

In a study conducted in 2003 with adolescents from public schools in the metropolitan area of Rio de Janeiro, a considerable prevalence of metabolic disorders was observed, particularly in those who were obese ${ }^{(4,5)}$, and an association was found between these disorders and anthropometric measurements of abdominal obesity ${ }^{(6)}$. Such evidence reinforces the importance of monitoring anthropometric measurements in adolescents.

In general, trends in overweight and obesity in adolescents have been evaluated based on $\mathrm{BMI}^{(7-11)}$. However, trends in anthropometric indicators of abdominal obesity such as waist circumference (WC), waist-to-hip ratio (WHR) and waist-to-height ratio (WHtR) have also been studied among adolescents. The increase in these measurements has been demonstrated in adolescents from various countries like Spain ${ }^{(12)}$, Australia ${ }^{(13)}$, the USA ${ }^{(14)}$, the $\mathrm{UK}^{(15,16)}$ and New Zealand ${ }^{(17)}$. In Brazil, studies on abdominal fat trends among adolescents have not been published yet.

The aim of the present study was to compare BMI, WC, WHR and WHtR in adolescents from public schools of a municipality in the metropolitan area of Rio de Janeiro, Brazil, between 2003 and 2008 . 


\section{Methods}

The analysis was based on data from two cross-sectional school-based surveys conducted in 2003 and 2008 with probabilistic samples of adolescents from public schools of Niterói, a city located in the metropolitan area of Rio de Janeiro, Brazil, with about 500000 inhabitants.

The survey conducted in 2003, which aimed to evaluate risk factors for CVD in adolescents, investigated a probabilistic sample of 610 adolescents (cluster sampling by random class selection) aged $12-19$ years, from 5 th to 11th grades in thirteen of the thirty-three public schools located in the city. The sample size estimation was based on the number of students enrolled in the state education system in Niterói in 2001 (25 102 students in the target age group). Details on sample design and selection can be found elsewhere ${ }^{(18)}$.

In 2008, there were 26294 students from 5th to 11th grades enrolled in the state education system in Niterói. To favour the comparability between the two studies, the same thirteen schools included in the first survey were included in the 2008 survey and thirty classes were randomly selected, with a mean expected number of thirty students per class. Therefore, 894 students aged 12-19 years were selected to participate in the survey. In both studies, the same criteria of eligibility were applied: not being pregnant and not having physical deficiencies which would hinder the anthropometric evaluation.

To verify the differences in the anthropometric measurements between the two studies, we opted for evaluating only those adolescents aged 15 years or older, considering that in this age range the changes observed would be less subjected to the effect of the sexual maturation, which can be especially variable between individuals particularly in the first phase of adolescence.

In 2003, there were 641 eligible students in the age group of 15-19 years, of which twenty-six parents did not sign the informed consent, seventy refused to participate in the research and fifteen did not come to school on the days scheduled for measurements. Therefore, 530 students were evaluated (non-response rate of $17 \cdot 3 \%$ ). In 2008, in the same age group, there were 632 eligible students of which thirty-three did not present the consent form signed by the legal guardian, seventy-four refused to participate in the research and twenty-seven did not come to school on the date scheduled for data collection. Therefore, 498 students were evaluated (non-response rate of $21 \cdot 2 \%$ ).

With these sample sizes, it was possible to estimate a prevalence of overweight of about $20 \%{ }^{(2)}$, with $95 \%$ confidence interval and 5\% absolute precision, considering the effect of the cluster design of sampling (classes) $^{(19)}$.

In both studies, interviewers were trained and standardized in anthropometric measurements within the margins of error accepted by Habicht's criterion ${ }^{(20)}$. When the interviewers did not reach the limit values for reliability and validity they underwent further standardization sessions to reach acceptable values. Interviewers were retrained periodically during the fieldwork using the same procedures. In the two surveys, body weight was measured using an electronic scale (Kratos PPS, Brazil) accurate to $50 \mathrm{~g}$. Height was measured with a portable stadiometer (Leicester model 2003, UK or Alturexata model 2008, Brazil) accurate to $0 \cdot 1 \mathrm{~cm}$. No significant differences were found between height means measured by the two stadiometers in twenty-five young adults $($ Leicester $=162 \cdot 5(\mathrm{SD} 9 \cdot 2) \mathrm{cm}$ and Alturexata $=162 \cdot 7$ (sD $9 \cdot 2) \mathrm{cm}, P=0 \cdot 93$ ).

The adolescents were evaluated wearing light clothing and barefoot, in orthostatic position. Due to the precision of the electronic scale, body weight was measured only once. Height was measured twice, considering the average of both measurements as the valid measure. A maximum variation of $0.5 \mathrm{~cm}$ between the two measurements was allowed, repeating the procedure if the difference was greater than this limit ${ }^{(21)}$. BMI was calculated dividing weight (in kilograms) by the square of height (in metres). Overweight prevalence was estimated by the age- and gender-specific BMI cut-offs ( $Z$-score $>1$ ) according to reference curves proposed by the $\mathrm{WHO}^{(22)}$.

WC and hip circumference (HC) were measured with inelastic tape measures, with variation of $0 \cdot 1 \mathrm{~cm}$, on the smallest trunk circumference (natural waist of the individual) and on the maximum circumference over the buttocks, respectively. Two measurements were taken for each circumference and the averages were considered as the valid measures. A maximum variation of $1.0 \mathrm{~cm}$ was allowed between both measurements, repeating the procedure if the difference was greater than the acceptable limit ${ }^{(23)}$.

The age-adjusted means with respective $95 \%$ confidence intervals, and the 3rd, 10th, 50th, 90th and 97th percentiles, of BMI, WC, HC, WHR and WHtR were estimated by sex and year of study. The means were compared by linear regression and frequencies were compared by the $\chi^{2}$ test. $P<0.05$ was taken as the level for a statistically significant difference. These statistical analyses were made considering the cluster sampling design (random classes) and the sampling expansion corrected by the relative weight, using the procedures for complex samples of the statistical software package SPSS version $19 \cdot 0$. Percentiles were compared by quantile regression using the statistical software package SAS version $9 \cdot 2$.

The study was conducted according to the guidelines laid down in the Declaration of Helsinki and all procedures involving human subjects were approved by the Research Ethics Committee of University Hospital Clementino Fraga Filho (for the survey conducted in 2003) and of Institute of Pediatrics Martagão Gesteira (for the survey conducted in 2008), both from the Federal University of Rio de Janeiro. The participation in the surveys was voluntary and only 
those adolescents who presented written informed consent signed by a legal guardian (for those under 18 years of age) took part in the research.

\section{Results}

Comparing the participants (530 students in 2003 and 498 students in 2008) with the non-participants (111 students in 2003 and 134 students in 2008), it was observed that there were no significant differences between participants and non-participants in 2003 with regard to gender and age range. In 2008 no differences were verified with regard to age range, but the proportion of boys was smaller among participants than among non-participants (Table 1).

There were no differences between the investigated groups in the 2003 and 2008 surveys according to gender (girls: $66.6 \%$ in $2003 v .59 \cdot 6 \%$ in $2008, P=0 \cdot 13$ ), age range (15-16 years: $44.5 \%$ in 2003 v. $53 \cdot 8 \%$ in 2008; 17-19 years: $55 \cdot 5 \%$ in $2003 v .46 \cdot 2 \%$ in $2008, P=0 \cdot 43$ ) and mean age (girls: $17 \cdot 1 v \cdot 16 \cdot 9$ years, $P=0 \cdot 55$; boys: $17 \cdot 3 v \cdot 16 \cdot 5$ years, $P=0 \cdot 12$ ).

A significant increase in girls' mean BMI $(P=0.03)$ and significant decreases in boys' mean WC $(P=0 \cdot 01)$ and HC $(P<0 \cdot 01)$ were observed between the two studies (Table 2).

In both studies conducted in 2003 and 2008, a high prevalence of overweight for boys and girls was observed; nevertheless, differences were dependent on gender. Although the results were not statistically significant, there was a tendency of increasing overweight among girls (15.9\% in 2003 v. $22 \cdot 2 \%$ in $2008, P=0 \cdot 11$ ),

Table 1 Comparison of participants and non-participants according to gender and age range: adolescents from public schools in the metropolitan area of Rio de Janeiro, Brazil, 2003-2008

\begin{tabular}{|c|c|c|c|c|c|}
\hline & \multicolumn{4}{|c|}{2003} & \multirow[b]{3}{*}{$P$ value } \\
\hline & \multicolumn{2}{|c|}{$\begin{array}{l}\text { Participants } \\
\text { (n 530) }\end{array}$} & \multicolumn{2}{|c|}{$\begin{array}{c}\text { Non-participants } \\
(n \text { 111) }\end{array}$} & \\
\hline & $n$ & $\%$ & $n$ & $\%$ & \\
\hline \multicolumn{6}{|l|}{ Gender } \\
\hline Male & 177 & $33 \cdot 4$ & 45 & $40 \cdot 5$ & \multirow[t]{2}{*}{0.15} \\
\hline Female & 353 & $66 \cdot 6$ & 66 & $59 \cdot 5$ & \\
\hline \multicolumn{6}{|l|}{ Age (years) } \\
\hline 15-16 & 236 & $44 \cdot 5$ & 55 & $49 \cdot 5$ & \multirow[t]{2}{*}{0.33} \\
\hline \multirow[t]{4}{*}{$17-19$} & 294 & $55 \cdot 5$ & 56 & $50 \cdot 5$ & \\
\hline & \multicolumn{4}{|c|}{2008} & \\
\hline & \multicolumn{2}{|c|}{$\begin{array}{l}\text { Participants } \\
\text { (n 498) }\end{array}$} & \multicolumn{2}{|c|}{$\begin{array}{c}\text { Non-participants } \\
(n \text { 134) }\end{array}$} & \\
\hline & $n$ & $\%$ & $n$ & $\%$ & $P$ value \\
\hline \multicolumn{6}{|l|}{ Gender } \\
\hline Male & 201 & $40 \cdot 4$ & 67 & $50 \cdot 0$ & \multirow[t]{2}{*}{0.045} \\
\hline Female & 297 & $59 \cdot 6$ & 67 & $50 \cdot 0$ & \\
\hline \multicolumn{6}{|l|}{ Age (years) } \\
\hline $15-16$ & 268 & $53 \cdot 8$ & 69 & $51 \cdot 5$ & \multirow[t]{2}{*}{0.63} \\
\hline $17-19$ & 230 & $46 \cdot 2$ & 65 & $48 \cdot 5$ & \\
\hline
\end{tabular}

whereas for boys the prevalence of overweight was not different between the two studies (19.8\% in $2003 v .19 \cdot 4 \%$ in 2008, $P=0.90$ ).

Based on the percentile distribution of anthropometric variables, it was observed that boys' WC, HC and WHtR curves were lower in 2008, whereas the BMI curves overlapped (Fig. 1) and the WHR curve was higher from the 50th percentile. For girls, the curves for all variables tended to be higher in 2008, except the WHR curve, which was higher only for the most elevated percentiles of the distribution (Fig. 2).

\section{Discussion}

In the present study we sought to know whether there were differences in means and percentile curves of BMI, WC, WHR and WHtR in adolescents from public schools of a municipality in the metropolitan area of Rio de Janeiro, Brazil, between 2003 and 2008. When we analysed the data, without stratifying by age group, we observed a significant increase in BMI for girls, but not for boys; and the same was observed for overweight prevalence. We also observed a tendency that boys' anthropometric measurements of abdominal obesity decreased between 2003 and 2008, whereas for girls they tended to increase. National representative surveys have already revealed that overweight and obesity have been increasing significantly in young Brazilians ${ }^{(2,10)}$. Based on a birth cohort study in Southern Brazil ${ }^{(24)}$, BMI in 15-year-old adolescents was positively associated with early rapid weight gain during early life, which can be a marker of high risk of obesity in older children and young adults. Nutrition during pregnancy as well as infant and young child feeding practices up until the child's second birthday (also referred to as 'the first 1000 days of life') should therefore receive priority attention in order to rectify this situation.

During the 2000s, Brazil has undergone profound changes in the socio-economic scenario. Economic growth and social policies for reducing poverty and improving income distribution have increased the population's purchasing power ${ }^{(25,26)}$ with important changes in the dietary pattern. For example, consumption of processed foods and sodas has increased, and thus may be related to increased rates of overweight and obesity in all age and sex groups in Brazil ${ }^{(27)}$. These changes affect the entire population, characterizing a period effect. However, a cohort effect may be present if children are compared with adolescents, showing a greater increase in prevalence of overweight and obesity in children ${ }^{(2)}$. This scenario may explain our findings when changes in mean BMI were analysed by stratifying our school data into two age groups: 15-17 years and 17-19 years (see Supplementary Materials). Mean BMI increased in the younger group by $0.6 \mathrm{~kg} / \mathrm{m}^{2}$ among boys and by 
Table 2 Variation in the means of anthropometric obesity indicators according to gender among adolescents from public schools in the metropolitan area of Rio de Janeiro, Brazil, 2003-2008

\begin{tabular}{|c|c|c|c|c|c|}
\hline \multirow[b]{3}{*}{ Variable } & \multicolumn{4}{|c|}{ Boys } & \multirow[b]{3}{*}{$P$ value* } \\
\hline & \multicolumn{2}{|c|}{$2003(n 177)$} & \multicolumn{2}{|c|}{2008 (n 201) } & \\
\hline & Mean & $95 \% \mathrm{Cl}$ & Mean & $95 \% \mathrm{Cl}$ & \\
\hline $\mathrm{BMI}\left(\mathrm{kg} / \mathrm{m}^{2}\right)$ & $21 \cdot 3$ & $20 \cdot 7,21 \cdot 9$ & $21 \cdot 2$ & $20 \cdot 7,21 \cdot 6$ & $0 \cdot 72$ \\
\hline WC $(\mathrm{cm})$ & $72 \cdot 9$ & $71 \cdot 8,74 \cdot 1$ & $70 \cdot 9$ & $69 \cdot 8,72 \cdot 0$ & 0.01 \\
\hline $\mathrm{HC}(\mathrm{cm})$ & $93 \cdot 1$ & $91 \cdot 9,94 \cdot 2$ & $90 \cdot 2$ & $89 \cdot 0,91 \cdot 4$ & $<0.01$ \\
\hline WHR & 0.78 & $0.78,0.79$ & 0.79 & $0.78,0.79$ & 0.51 \\
\hline WHtR & 0.42 & $0.41,0.43$ & 0.41 & $0.40,0.42$ & $0 \cdot 17$ \\
\hline
\end{tabular}

\begin{tabular}{|c|c|c|c|c|c|}
\hline & \multicolumn{4}{|c|}{ Girls } & \multirow[b]{3}{*}{$P$ value* } \\
\hline & \multicolumn{2}{|c|}{$2003(n 353)$} & \multicolumn{2}{|c|}{2008 (n 297) } & \\
\hline & Mean & $95 \% \mathrm{Cl}$ & Mean & $95 \% \mathrm{Cl}$ & \\
\hline BMI $\left(\mathrm{kg} / \mathrm{m}^{2}\right)$ & $21 \cdot 1$ & $20 \cdot 5,21 \cdot 7$ & $22 \cdot 0$ & $21 \cdot 4,22 \cdot 5$ & 0.03 \\
\hline$W C(\mathrm{~cm})$ & $67 \cdot 5$ & $66 \cdot 3,68 \cdot 7$ & $68 \cdot 1$ & $66 \cdot 9,69 \cdot 2$ & 0.51 \\
\hline $\mathrm{HC}(\mathrm{cm})$ & $93 \cdot 2$ & $92 \cdot 0,94 \cdot 4$ & $94 \cdot 3$ & $93 \cdot 3,95 \cdot 2$ & $0 \cdot 18$ \\
\hline WHR & 0.72 & $0.72,0.73$ & 0.72 & $0.72,0.73$ & 0.65 \\
\hline WHtR & 0.42 & $0 \cdot 10,0 \cdot 43$ & 0.42 & $0.42,0.43$ & 0.39 \\
\hline
\end{tabular}

WC, waist circumference; HC, hip circumference; WHR, waist-to-hip ratio; WHtR, waist-to-height ratio. *Obtained by linear regression.

$1 \cdot 4 \mathrm{~kg} / \mathrm{m}^{2}$ among girls, whereas for the older group these changes in mean BMI were negligible in girls $\left(0 \cdot 2 \mathrm{~kg} / \mathrm{m}^{2}\right)$ and even showed a reduction among boys $\left(-0.4 \mathrm{~kg} / \mathrm{m}^{2}\right)$. These changes are in accordance with an important cohort effect: the younger group showing a higher increase in BMI, and the older group showing an increase in BMI only when compared within their own cohort (i.e. those who were younger in 2003), but not when compared with the younger group in 2008.

The stabilization of overweight prevalence in boys could also have resulted from a possible higher level of physical activity among boys compared with girls. Even though we did not analyse physical activity data, it is possible that the boys were more active than the girls as observed by a systematic review ${ }^{(28)}$ and a Brazilian nationwide surveillance study ${ }^{(29)}$.

In general, percentile values of girls' anthropometric measurements increased between 2003 and 2008, except for WHR, which increased only for the highest percentiles of the distribution. Using WHR to estimate abdominal fat accumulation in adolescents is highly dependent on age ${ }^{(30)}$ and the changes in WHR during pubertal development might be reflecting changes in the relationship between the measures of waist and hip, more than properly central accumulation of fat ${ }^{(31)}$. WHR presented poorer performance in the prediction of abdominal fat evaluated by dual-energy X-ray absorptiometry than WC in children aged 3-19 years ${ }^{(32)}$. In contrast, WHtR has been recommended for adolescents because besides being independent of sex and age, it is considered a good marker to monitor overweight for young subjects ${ }^{(14,33)}$. This index is also highly correlated to visceral fat ${ }^{(34)}$ and with risk factors for metabolic syndrome in children ${ }^{(35)}$. In the students evaluated in the 2003 study, WHtR was the second measure of abdominal fat more closely associated with the components of metabolic syndrome; WC presented the best results while WHR was the one with the poorest association $^{(6)}$.

The present study therefore demonstrated that, for girls, besides the increase in total body fat reflected by the differences in BMI, there was also a trend of abdominal obesity increase as suggested by percentile distributions of WC and WHtR (Fig. 2b and e), which could indicate a higher risk of metabolic disorders associated with the excess of central body fat.

In boys, 2003 and 2008 BMI curves overlapped (Fig. 1a). There was even a tendency of lower fat accumulation in the abdominal region expressed by lower values of WC and WHtR percentiles in 2008 (Fig. 1b and e). The only exception was for WHtR 97th percentile, which was higher in the second study. The higher values for the 2008 boys' WHR 50th percentile may be explained by the lower average $\mathrm{WC}$, resulting in higher values for the ratio between these measures of waist and hip. However, this finding does not seem to have any clinical relevance.

Studies analysing trends in percentile distributions of anthropometric indicators of abdominal obesity in young people are scarce, thus limiting the possibility of comparing the results observed in the present study. Studies that evaluated temporal changes in WC and WHtR measures in adolescents have compared averages and demonstrated an increase in these measures, both for boys and girls ${ }^{(12-17)}$.

Evaluating the BMI of adolescents in Belgium, between 1969 and 1996 Hulens et al. ${ }^{(36)}$ observed an increase in the values of this index between the lowest and the 

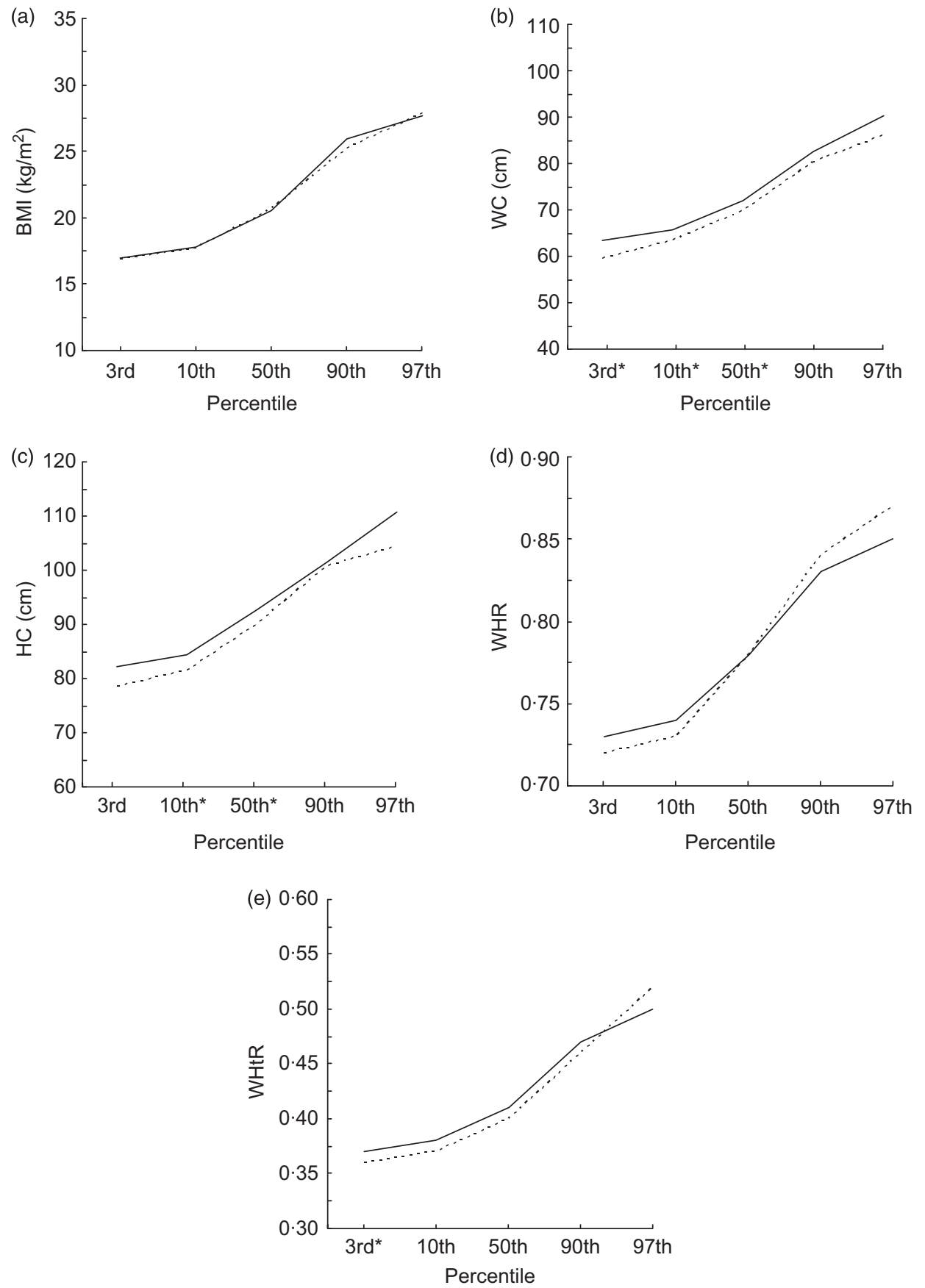

Fig. 1 Variation in the percentiles of anthropometric obesity indicators among male adolescents from public schools in the metropolitan area of Rio de Janeiro, Brazil, 2003 (-) to 2008 (- - -): (a) BMl; (b) waist circumference (WC); (c) hip circumference (HC); (d) waist-to-hip ratio (WHR); (e) waist-to-height ratio (WHtR). Significant difference between 2003 and 2008 obtained by quantile regression: ${ }^{*} P<0.05$

highest percentiles for girls and only in the highest percentiles (85th and 95th) for boys. Kautiainen et al. ${ }^{\text {(37) }}$ also noted an increase between 1977 and 1999 in the 85th and 95th BMI percentiles of Finnish girls and boys.

It is important to highlight that the absolute values of the 90th percentile of BMI both in $2003\left(25.9 \mathrm{~kg} / \mathrm{m}^{2}\right.$ for boys and $25 \cdot 3 \mathrm{~kg} / \mathrm{m}^{2}$ for girls) and in $2008\left(25 \cdot 2 \mathrm{~kg} / \mathrm{m}^{2}\right.$ for boys and $26 \cdot 8 \mathrm{~kg} / \mathrm{m}^{2}$ for girls) were already higher than the cut-off point indicated by $\mathrm{WHO}^{(38)}$ to classify overweight in adults $\left(25 \cdot 0 \mathrm{~kg} / \mathrm{m}^{2}\right)$. Likewise, the 97 th percentile of WHtR both in $2003(0.50$ for boys and 0.51 for girls $)$ and in $2008(0.52$ for boys and 0.54 for girls $)$ were equal to or greater than the cut-off point suggested to indicate risk of CVD $(0 \cdot 50)^{(16)}$.

The sample size in the present study did not allow the comparison of changes between anthropometric indicators 

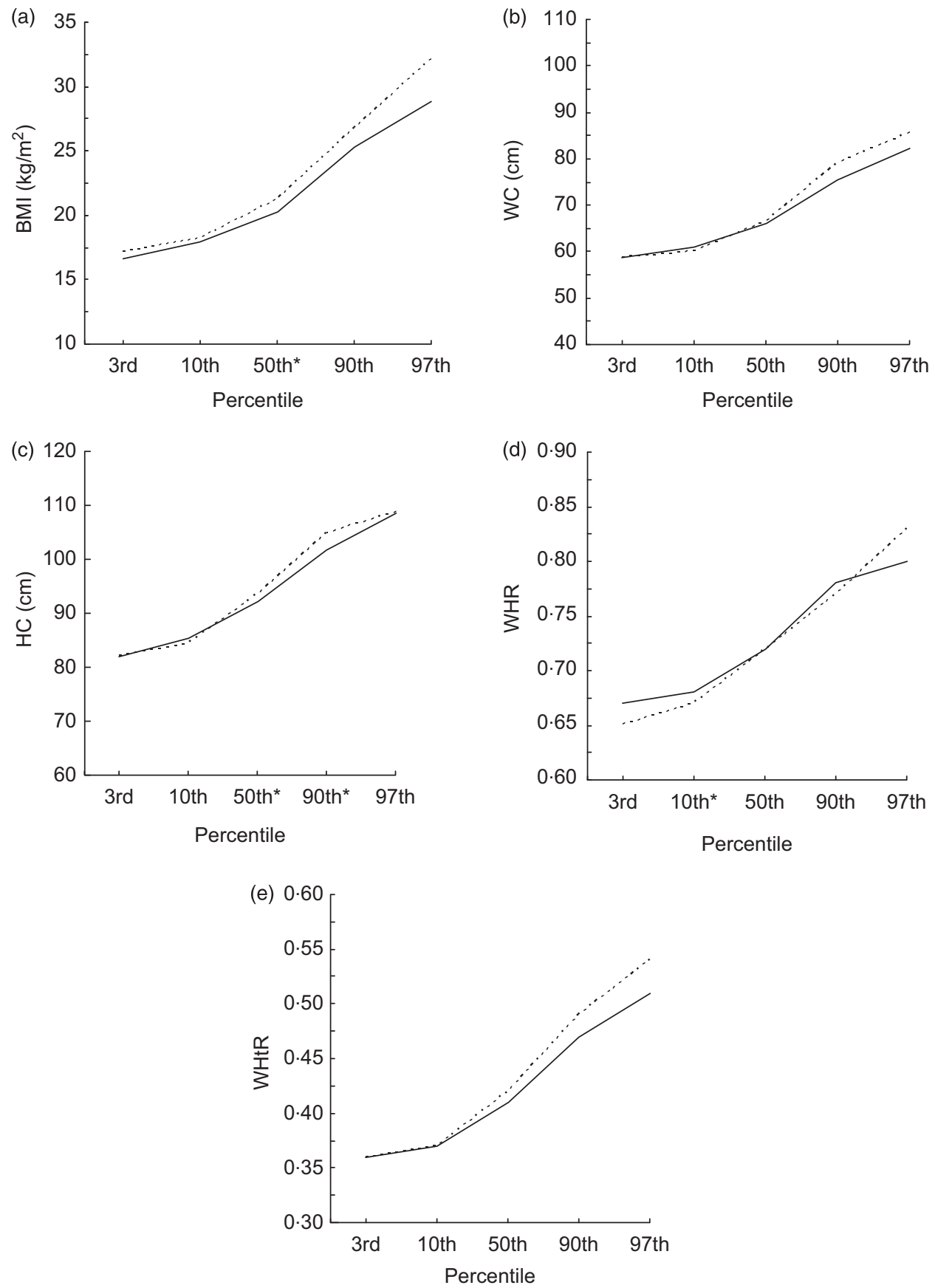

Fig. 2 Variation in the percentiles of anthropometric obesity indicators among female adolescents from public schools in the metropolitan area of Rio de Janeiro, Brazil, 2003 (-) to 2008 (----): (a) BMl; (b) waist circumference (WC); (c) hip circumference (HC); (d) waist-to-hip ratio (WHR); (e) waist-to-height ratio (WHtR). Significant difference between 2003 and 2008 obtained by quantile regression: ${ }^{\star} P<0.05$

for each year of age, which would be recommended due to the variation in anthropometric measurements with the growth process. This limitation has been softened by adjusting the measurements by age. Despite this limitation, we can confirm the importance of monitoring the nutritional status of adolescents based on anthropometric measurements, a method which is characterized by its practicality and low costs. Therefore this should be implemented in the routine health-care service for children and adolescents, including in the school environment, aiming at better control and prevention of nutritional problems.

The present results revealed that, between 2003 and 2008, among girls from Niterói, Rio de Janeiro, there was a significant increase in mean BMI and a tendency for anthropometric indicators of abdominal obesity to increase. 
However, among boys, there was stabilization in these measures. Further analysis suggested that a cohort effect may have a role in this phenomenon. Therefore, new studies that could clarify gender differences in the evolution of anthropometric indicators of adolescents in the metropolitan region investigated would be important.

\section{Acknowledgements}

Sources of funding: This research was supported by the Conselho Nacional de Desenvolvimento Científico e Tecnológico (CNPq) and the Fundação Carlos Chagas Filho de Amparo à Pesquisa do Estado do Rio de Janeiro (FAPERJ). Conflicts of interest: There are no conflicts of interest to declare. Authors' contributions: E.G.B. analysed data, interpreted the results and led the writing; R.A.P. assisted with data analysis, interpretation of the data and revised the text; R.S. assisted with data analysis, interpretation of the data and revised the text; G.V.d.V. originated the study, supervised all aspects of analysis and interpretation of the data and revised the text.

\section{Supplementary Materials}

For Supplementary Materials for this article, please visit http://dx.doi.org/10.1017/S1368980012005198

\section{References}

1. Wang Y \& Lobstein T (2006) Worldwide trends in childhood overweight and obesity. Int J Pediatr Obes 1, 11-25.

2. Instituto Brasileiro de Geografia e Estatística (2010) Pesquisa de Orçamentos Familiares, 2008-2009: Antropometria e Estado Nutricional de Crianças, Adolescentes e Adultos no Brasil. Rio de Janeiro: IBGE.

3. Sichieri R, Veiga GV, Souza RA et al. (2009) School randomised trial on prevention of excessive weight gain by discouraging students from drinking sodas. Public Health Nutr 12, 197-202.

4. Alvarez MM, Vieira ACR, Moura AS et al. (2006) Insulin resistance in Brazilian adolescent girls: association with overweight and metabolic disorders. Diabetes Res Clin Pract 74, 183-188.

5. Alvarez MM, Vieira ACR, Sichieri R et al. (2011) Prevalence of metabolic syndrome and of its specific components among adolescents from Niterói City, Rio de Janeiro State, Brazil. Arq Bras Endocrinol Metab 55, 164-170.

6. Alvarez MM, Vieira ACR, Sichieri R et al. (2008) Associação das medidas antropométricas de localização de gordura central com os componentes da síndrome metabólica em uma amostra probabilística de adolescentes de escolas públicas. Arq Bras Endocrinol Metab 52, 649-657.

7. Chinn S \& Rona RJ (2001) Prevalence and trends in overweight and obesity in three cross sectional studies of British children, 1974-1994. BMJ 322, 24-26.

8. Wang Y, Monteiro C \& Popkin BM (2002) Trends of obesity and underweight in older children and adolescents in the United States, Brazil, China and Russia. Am J Clin Nutr $\mathbf{7 5}$, 971-977.

9. Heude B, Lafay L, Borys JM et al. (2003) Time trend in height, weight, and obesity prevalence in school children from Northern France, 1992-2000. Diabetes Metab 29, 235-240.
10. Veiga GV, Cunha AS \& Sichieri R (2004) Trends in overweight among adolescents living in the poorest and richest regions of Brazil. Am J Public Health 94, 1544-1548.

11. Ogden CL, Carroll MD, Curtin LR et al. (2006) Prevalence of overweight and obesity in the United States, 1999-2004. JAMA 295, 1549-1555.

12. Moreno LA, Sarria A, Fleta J et al. (2005) Secular trends in waist circumference in Spanish adolescents, 1995 to 2000-02. Arch Dis Child 90, 818-819.

13. Garnett SP, Cowell CT, Baur LA et al. (2005) Increasing central adiposity: the Nepean longitudinal study of young people aged 7-8 to 12-13y. Int J Obes (Lond) 29, 1353-1360.

14. Li C, Ford ES, Mokdad AH et al. (2006) Recent trends in waist circumference and waist-height ratio among US children and adolescents. Pediatrics 118, 1390-1398.

15. McCarthy HD, Ellis SM \& Cole TJ (2003) Central overweight and obesity in British youth aged 11-16 years: cross sectional surveys of waist circumference. BMJ 326, 624 .

16. McCarthy HD \& Ashwell M (2006) A study of central fatness using waist-to-height ratios in UK children and adolescents over two decades supports the simple message 'keep your waist circumference to less than half your height'. Int J Obes (Lond) 30, 988-992.

17. Utter J, Scragg R, Denny S et al. (2009) Trends in body mass index and waist circumference among New Zealand adolescents, 1997/1998-2005. Obes Rev 10, 378-382.

18. Vieira ACR, Alvarez MM, Kanaan S et al. (2009) Body mass índex for predicting hyperglycemia and serum lipid changes in Brazilian adolescents. Rev Saude Publica 43, 44-52.

19. Lwanga SK \& Lemeshow S (1991) One-sample situations. In Sample Size Determination in Health Studies: A Practical Manual, pp. 1-5 [SK Lwanga and S Lemeshow, editors]. Geneva: WHO.

20. Habicht JP (1974) Estandarizacion de metodos epidemiologicos sobre el terreno. Bol Oficina Sanit Panam 76, 375-381.

21. Gordon CC, Chumlea WC \& Roche AF (1988) Stature, recumbent length and weight. In Anthropometric Standardization Reference Manual, pp. 3-8 [TG Lohman, AF Roche and R Martorell, editors]. Champaign, IL: Human Kinetics Books.

22. Onis M, Onyango AW, Borghi E et al. (2007) Development of a WHO growth reference for school-aged children and adolescents. Bull World Health Organ 85, 660-667.

23. Callaway CW, Chumlea WC, Bouchard C et al. (1988) Circumferences. In Anthropometric Standardization Reference Manual, pp. 39-54 [TG Lohman, AF Roche and R Martorell, editors]. Champaign, IL: Human Kinetics Books.

24. Menezes AMB, Hallal PC, Dumith SC et al. (2012) Adolescent blood pressure, body mass index and skin folds: sorting out the effects of early weight and length gains. J Epidemiol Community Health 66, 149-154.

25. Ministério da Fazenda, Brasil (2010) A Economia Brasileira em Perspectiva (The Brazilian Economy in Perspective). Edição Especial 2010. http://www.fazenda.gov.br/portugues/ docs/perspectiva-economia-brasileira/edicoes/EconomiaBrasileira-Em-Perspectiva-Especial-10.pdf (accessed July 2012).

26. Fecomercio SP (2012) A evolução da classse média e o seu impacto no varejo: diagnósticos e tendências (The evolution of the middle class and its impact on retail: diagnostics and trends). http://www.fecomercio.com.br/ arquivos/arquivo/estudo_da_classe_media_fevereiro_2012_ ljiaiah9aa.pdf (accessed July 2012).

27. Monteiro CA \& Cannon G (2012) The impact of transnational 'Big Food' companies on the South: a view from Brazil. PLoS Med 9, e1001252.

28. Seabra AF, Mendonça DM, Thomis MA et al. (2008) Determinantes biológicos e sócio-culturais associados à prática de atividade física de adolescentes. Cad Saude Publica 24, 721-736. 
29. Hallal PC, Knuth AG, Cruz DKA et al. (2010) Prática de atividade física em adolescentes brasileiros. Cienc Saude Colet 15, 3035-3042.

30. Power C, Lake JK \& Cole TJ (1997) Measurement and longterm health risks of child and adolescent fatness. Int J Obes Relat Metab Disord 21, 507-526.

31. Weiss R, Dziura J, Burgert TS et al. (2004) Obesity and the metabolic syndrome in children and adolescents. N Engl J Med 350, 2362-2374.

32. Taylor RW, Jones IE, Williams SM et al. (2000) Evaluation of waist circumference, waist-to-hip ratio, and the conicity index as screening tools for high trunk fat mass, as measured by dual-energy X-ray absorptiometry, in children aged 3-19 y. Am J Clin Nutr 72, 490-495.

33. Vander KK \& Seidell JC (1993) Techniques for the measurement of visceral fat: a practical guide. Int J Obes Relat Metab Disord 17, 187-196.
34. Ashwell MA, Lejeune SRE \& McPherson B (1996) Ratio of waist circumference to height may be better indicator of need for weight management. BMJ 312, 377.

35. Savva SC, Tornaritis M \& Savva ME (2000) Waist circumference and waist-to-weight ratio are better predictors of cardiovascular disease risk factors in children than body mass index. Int J Obes Relat Metab Disord 24, 1453-1458.

36. Hulens M, Beunen G, Claessens AL et al. (2001) Trends in BMI among Belgian children, adolescents and adults from 1969 to 1996. Int J Obes Relat Metab Disord 25, 395-399.

37. Kautiainen S, Rimpelä A, Vikat A et al. (2002) Secular trends in overweight and obesity among Finnish adolescents in 1977-1999. Int J Obes Relat Metab Disord 26, 544-552.

38. World Health Organization (2004) Obesity: Preventing and Managing the Global Epidemic. Report of a WHO Consultation on Obesity. WHO Technical Report Series no. 894. Geneva: WHO. 